\title{
Cosmetic Outcome and Patient Satisfaction in Oncoplastic Breast Conserving Surgery: Reply to Letter to the Editor
}

\author{
Sharon W. W. Chan - Polly S. Y. Cheung • \\ S. H. Lam
}

Published online: 5 May 2010

(C) Société Internationale de Chirurgie 2010

To the Editor:

We thank Dr. Bulam, Dr. Tuncer, and Dr. Ayhan [1] for their interest in our article [2]. We agree that the proposed calculation of percentage of breast volume excision, which is calculated by dividing the specimen's weight by the estimated breast volume, is not perfect. Although there are various ways to estimate breast volume, most are considered cumbersome or inaccurate [3]. We use specimen weight for specimen volume because it is proportional to actual specimen volume [4] and it can be measured accurately and readily intraoperatively. We acknowledge that breast density varies from breast to breast; it can be mainly fatty tissues $\left(0.916 \mathrm{~g} / \mathrm{cm}^{3}\right)$ or mainly fibroglandular tissues $\left(1 \mathrm{~g} / \mathrm{cm}^{3}\right)$. If different breast density is taken into account in our calculation, the maximum error of the calculation of the excised breast volume or percentage of breast volume excision is $9 \%$. As our calculated percentage of breast volume excision ranges from 1 to $42 \%$, this systematic error (i.e., $1 \pm 0.09 \%$ to $42 \pm 3.78 \%$ ) is considered to be small. Although our stated cutoff point of $20 \%$ may change to $18-22 \%$, it should not affect the point of discussion of our article.

\section{References}

1. Bulam H, Tuncer S, Ayhan S (2010) Cosmetic outcome and percentage of breast volume excision in oncoplastic breast conserving surgery: a proposal. World J Surg 34: doi:10.1007/s00268010-0523-3

2. Chan SW, Cheung PY, Lam SH (2010) Cosmetic outcome and percentage of breast volume exicsion in oncoplastic breast conserving surgery. World J Surg 34: doi:10.1007/s00268-0090278-x

3. Cochrane RA, Valasiadou P, Wilson AR (2003) Cosmesis and satisfaction after breast-conserving surgery correlates with the percentage of breast volume excised. Br J Surg 90:1505-1509

4. Sheamoun JM, Hartrampf CR (1996) Mastectomy specimen weight and skin dimensions as an adjunct in breast reconstruction. Ann Plast Surg 36:251-254
S. W. W. Chan $(\varangle) \cdot$ S. H. Lam

Kowloon East Cluster Breast Centre, Department of Surgery,

United Christian Hospital, Kwun Tong, Hong Kong SAR,

People's Republic of China

e-mail: sharonwwchan@yahoo.com

\section{P. S. Y. Cheung}

Hong Kong Sanatorium and Hospital, Hong Kong SAR,

People's Republic of China 